Journal of Advanced Research in Fluid Mechanics and Thermal Sciences

Journal homepage: www.akademiabaru.com/arfmts.html ISSN: 2289-7879

\title{
Numerical Simulation of Natural Convection in A Cavity Filled with A Nanofluid Who's Wall Containing the Heat Source Is Inclined
}

\author{
Jamal Ghouizi ${ }^{1, *}$, Mohamed Nabou ${ }^{1}$, Mohammed Elmir $^{1}$, Mohamed Douha ${ }^{1}$, Mehdi Berramdane ${ }^{1}$ \\ ENERGARID Laboratory, Faculty of Technology, TAHRI Mohamed University of Bechar, B.P.417, 08000, Bechar, Algeria
}

\section{ARTICLE INFO $\quad$ ABSTRACT}

\section{Article history:}

Received 29 March 2020

Received in revised form 12 June 2020

Accepted 20 June 2020

Available online 8 October 2020

\section{Keywords:}

Natural convection; Nanofluid; Cooling;

Finite Elements Method; Numerical

Simulation

\begin{abstract}
In this work, a numerical study of natural convection in a trapezoidal cavity with aspect ratio $A$, filled with a nanofluid whose wall containing the square heat source of side dimensionless $\varepsilon=0.1$ is successively inclined at an angle $\gamma$ varying from 0 to $60^{\circ}$ at the most (in order to maintain a valid model straight vertical wall) with respect to the horizontal. The upper and lower walls on either side of the heat source are adiabatic while the other walls are subjected to a constant cold temperature. The hydrodynamic and thermal phenomena are described by the equations of Navier-Stokes and energy. The models Brinkman and Wasp are used to describe the thermo-physical properties of the nanofluid (water- $\mathrm{Al}_{2} \mathrm{O}_{3}$ ). The finite element method; based on the Galerkin principle; is used to solve the system of partial differential equations. the effect of the solid volume fraction and the angle of inclination of the lower wall for different values of the Rayleigh number on the results obtained, are considered in the form of isotherms, local and average modified Nusselt numbers.
\end{abstract}

\section{Introduction}

Some studies made ten years ago, in the field of heat transfer, have shown that in certain conditions, adding nanometric particles in a fluid (called nanofluid), as in the case of particles of Aluminum oxide $\left(\mathrm{Al}_{2} \mathrm{O}_{3}\right)$, copper $(\mathrm{Cu})$ or silver $(\mathrm{Ag})$, where some carbon nanotubes mixed with water, could increase heat transfer in comparison with the case of a pure element (water) with changes in the carrier fluid thermal conductivity.

The term "nanofluid" was initially suggested by Choi [1] to design at the suspension of solid nanoparticles in a basic liquid, he has found that the effective thermal conductivity of the mixture (water- $\mathrm{Al}_{2} \mathrm{O}_{3}$ ) increases by $20 \%$ for a volume concentration between $1 \%$ and $5 \%$ of $\mathrm{Al}_{2} \mathrm{O}_{3}$.

\footnotetext{
* Corresponding author.

E-mail address: ghouizi.08@gmail.com
}

https://doi.org/10.37934/arfmts.76.1.116 
In addition, Choi et al., [2] have observed that mixing certain types of nanoparticles within a fluid, even in a very weak concentration ( $1 \%$ in volume), can increase its thermal conductivity by $150 \%$ in case of carbon nanotubes, and by $40 \%$ for copper oxide nanoparticles, Eastman et al., [3].

Studies were carried out since 2001 on nanofluids to obtain better understanding of their underlying mechanisms. Nanofluids strong thermal conductivity make them potential substitutes of carrier fluids, usually used in thermal exchangers, to improve these latter's performance, Keblinski [4].

Furthermore, lack of stability of certain nanofluids over time can cause nanoparticles agglomeration and thermal conductivity variations. However, current researches confirm that the two effects remain less important when using nanofluids than in the case of suspension of ordinary microparticles Daungthongsuk [6]. Nanofluids thermal properties are not compatible with expectations given by traditional theories describing solid particles suspensions in a liquid.

Despite the number us studies published in this subject recently, no theoretical work was able to describe properly experimental results obtained for nanofluids, according to Vadasz [7].

The first research on thermal conductivity improvement using aluminum oxide $\left(\mathrm{Al}_{2} \mathrm{O}_{3}\right)$ was carried out by Massuda et al., [8] in 1993 by means of adding nanoparticles $\left(\mathrm{Al}_{2} \mathrm{O}_{3}\right)$ of $13 \mathrm{~nm}$ diameter, an improvement of $30 \%$ has been achieved in thermal conductivity for a volume fraction of $\varphi=4.3 \%$. This study was followed by another one performed by Eastman et al., [9] who noticed an improvement of $30 \%$ in thermal conductivity of $\left(\mathrm{Al}_{2} \mathrm{O}_{3}\right)$ nanoparticles of $33 \mathrm{~nm}$ diameter in water for a volume fraction of $5 \%$.

The work of Wang et al., [10] was based on a numerical study of natural convection within a bidimensional cavity for different numbers of Grashof and for different volume concentrations. A thermal conductivity improvement by $40 \%$ was obtained for (ethanol glycol- $\mathrm{Al}_{2} \mathrm{O}_{3}$ ) with a volume fraction of $8 \%$, and $14 \%$ for (water- $\mathrm{Al}_{2} \mathrm{O}_{3}$ ) for a volume fraction of $4.5 \%$.

Lee et al., [11] measured nanofluids thermal conductivity using copper oxide $\mathrm{CuO}$ and aluminum oxide $\mathrm{Al}_{2} \mathrm{O}_{3}$. These particles were used in two basic liquids: water and ethanol glycol, a $10 \%$ improvement in thermal conductivity was obtained for (water- $\mathrm{Al}_{2} \mathrm{O}_{3}$ ) nanofluid with a volume fraction of $4.3 \%$ and a $20 \%$ improvement for $\left(\mathrm{Al}_{2} \mathrm{O}_{3}\right)$ in ethanol glycol for $\varphi=5 \%$ volume fraction. These results are remarkably diffrent from those obtained by previous authors even if these latter used same size nanoparticles.

In 2003, Das et al., [12] were the first to study temperature effect on thermal conductivity raise of nanofluids. They noticed an increase in thermal conductivity when temperature varies from $21^{\circ} \mathrm{C}$ to $51{ }^{\circ} \mathrm{C}$ for both nanofluids (water- $\mathrm{Al}_{2} \mathrm{O}_{3}$ ) and (water-CuO) with particles of $38.4 \mathrm{~nm}$ and $28.6 \mathrm{~nm}$ diameters respectively. Experimental results indicated that thermal conductivity increased proportionally (linear variation) with the increase in temperature but depending on nanoparticles volume fraction in water. It was noticed that the obtained experimental results varied greatly from one research to another, something that does not allow direct comparison between these results and theoretical ones.

This study was carried in 2009 by Ögüt [13] to study the heat transfer by natural convection of water-based nanofluids in an inclined square enclosure for different lengths of the heat source and Rayleigh numbers where the left vertical side is heated with a constant heat flux, the right side is cooled, and the other sides are kept adiabatic. He solved the equations governing natural convection using a polynomial differential quadrature (PDQ) method.

In 2011, Fontana et al., [14] studied a constant air flow driven by buoyancy in a partially open square 2D cavity with internal heat source. Interesting results have been obtained whose complete analysis ends with horizontal curves of air speed and opening temperature. The numerical results show a significant influence of the opening on the heat transfer in the cavity. 
The buoyancy-driven fluid flow and heat transfer in a square cavity with partially active side walls filled with Cu-water nanofluid are studied numerically by Sheikhzadeh et al., [15]. The results show that the mean Nusselt number increases with increasing both the Rayleigh number and the volume fraction of the nanoparticles. In addition, the Nusselt maximum mean number for the high and low Rayleigh numbers occurs for the lower-middle and middle-middle locations of the thermally active parts, respectively.

The buoyancy-induced heat transfer and fluid flow in a triangular enclosure are investigated both numerically and experimentally by Oztop et al., [16] experimental and numerical results show good agreement. They observed that inclination angle can be used as a control parameter for heat transfer.

The article provided by Aminossadati [17] presents a numerical analysis of the natural cooling of a right triangular heat source by a water- $\mathrm{CuO}$ nanofluid in a right triangular cavity that is under the influence of a horizontal magnetic field. The effects of the Rayleigh, solid volume fraction, Hartmann number and the position of the heat source in the cavity on the heat transfer performance of the cavity are examined. The thermal performance of the cavity is enhanced as the Rayleigh number increases, the Hartmann number decreases and the distance of the heat source with the cold walls decreases. An optimum solid volume fraction is found that maximizes the heat transfer at high Rayleigh numbers.

A numerical investigation of natural convection in a $\mathrm{Cu}$-water nanofluids-filled eccentric annulus with a constant heat flux wall made in 2017 by Yang Hu et al., [18]. Influences of Rayleigh number $\left(10^{3} \leq \mathrm{Ra} \leq 10^{7}\right)$, eccentricity $(\varepsilon=-0.625,0$ and 0.625$)$, nanoparticles volume fraction $(0 \leq \varphi \leq 0.03)$ and radial ratio ( $r r=2.33,2.6$ and 3 ) on the on streamlines, isotherms and Nusselt number are studied. It is noted that the inclusion of the nanoparticles into pure fluid changes the flow pattern. And the Nusselt number has a positive relationship with nanoparticles volume fraction, Rayleigh number and radial ratio. Also, it can be confirmed that Nusselt number in the case with negative eccentricity $(\varepsilon=-0.625)$ is larger than the others.

In this research, a numerical study was carried out on heat transfer by natural convection of two nanofluids in a partially heated horizontal cylindrical enclosure in 2018 by Guestala et al., [19]. The partial heating occurs through the lower side of the enclosure at a constant temperature. The length of the heat source is changed from $5 \%$ to $25 \%$ of the total perimeter of the enclosure. The two side parts of the enclosure are maintained at a low constant temperature, each one of them has a length of $25 \%$ of the total perimeter. The top part of the enclosure is considered as adiabatic, it has a length of $25 \%$ of the total perimeter. The two nanofluids used are $\mathrm{Cu}$-water and $\mathrm{TiO}_{2}$-water with a volume fraction of nanoparticles being varied in the range of $0-0.05$. The Rayleigh number was varied in the interval $10^{3}$ to $10^{6}$. The results obtained were summarized in the form of correlation equations of the average Nusselt number as a function of the heated length, the Rayleigh number and volume fraction for both types of nanofluids.

In 2019, Ferhi, Djebali and Abboudi [20] have studied numerically the natural convection conjugated inside a square cavity filled with nanofluid $\mathrm{Al}_{2} \mathrm{O}_{3}$-water and partitioned by an exchange of thickness $\delta$, differentially heated at the level of the vertical walls, the other parts are adiabatic. The results obtained show an increase in heat transfer as a function of the increase in temperature, while it is underestimated as a function of the increase in the volume fraction and in the size of the nanoparticles $\mathrm{Al}_{2} \mathrm{O}_{3}$ (for $\mathrm{dp} \geq 35 \mathrm{~nm}$ ) due to the reduction in the effective Rayleigh number Ra * and the dynamic viscosity is an important factor in improving heat transfer, particularly in partitioned cavities.

The article presented by Sawicka et al., [21] in 2019 deals with natural convection around a circular cylinder with constant heat flux in a cavity using computation fluid dynamics. As ethylene glycol with nanoparticles $\mathrm{Al}_{2} \mathrm{O}_{3}$ for different mass concentrations and number of Rayleigh. The 
nanofluids are modeled with single-phase approach. For the investigated range of nanoparticle concentration, the influence of concentration on Nusselt, Rayleigh number and heat transfer coefficient are small. Nevertheless, a slight shift towards lower Nusselt, Rayleigh numbers and an increase in heat transfer coefficient occur. The Nusselt number depends on Rayleigh number and only negligible on Prandtl number, which is in accordance with literature for Prandtl numbers of around 200.The numerical results obtained are compared with own preliminary experimental data, deviations are discussed.

Knowing that the position of the heat source is assumed to be fixed in the middle of the inclined lower wall of the trapezoidal cavity considered, the main objective of this study is to evaluate the possibilities of improving the heat transfer in this thermal chamber containing a nanofluid relative to a square cavity $(\gamma=0)$, by increasing the rate of the volume fraction thereof and the angle of inclination of the lower wall of the cavity. For a fractional volume fraction and an optimal angle of inclination, understanding of the fundamental mechanisms involved in these modes of heat transfer from a dynamic and thermal field simulation approach.

This process of heat transfer by natural convection takes place in the rooms heated, factory halls, green houses, cooled storage containers food, clean rooms, underground coal gasification cavities, flat plate solar collectors, nuclear reactor tanks or vessels of waste, densely packed dissipation microelectronics, cavity walls and the double glazing of the windows.

\section{Methodology}

\subsection{Simplifying Assumption}

It is now necessary to make a number of assumptions simplifiers to establish a simple mathematical model (2D) that describes physics of this problem, to simplify the calculation (to save computational time), and get results earlier with the condition that his last put forward would not compromise the quality of the final result. So, we adopt the following hypotheses

i. The flow considered is stationary.

ii. The fluid is Newtonian and incompressible.

iii. Steady state heat transfer.

iv. The heat transfer by radiation is negligible.

v. The work, induced by viscous and pressure forces, is negligible.

vi. The thermo-physical properties of the fluid (supposed to be ideal) are constant except for the mass volume which obeys the Boussinesq approximation in the term of the thrust of Archimedes.

vii. The power density dissipated is negligible.

\subsection{Physical Model and Governing Equation}

\subsubsection{Physical model}

Figure 1 demonstrates a trapezoidal cavity which has the same volume and surface with respect to a square cavity of characteristic length $L$, filled with a nanofluid (water-aluminum oxide) and subjected to a natural convection, its walls verticals are maintained at a constant cold temperature $\mathrm{T}_{\mathrm{c}}$, while the other walls are adiabatic. The heat source is maintained at a constant hot temperature $\mathrm{T}_{\mathrm{h}}$.

The nanofluid used is assumed to be isotropic and homogeneous with constant thermo-physical properties. The flow is two-dimensional and laminar. The approximation of Boussinesq is adopted. 
The $\mathrm{Al}_{2} \mathrm{O}_{3}$ solid nanoparticles used have a spherical shape and are supposed to be stable and suspended in water, means that there was no sedimentation or accumulation of nanoparticles.

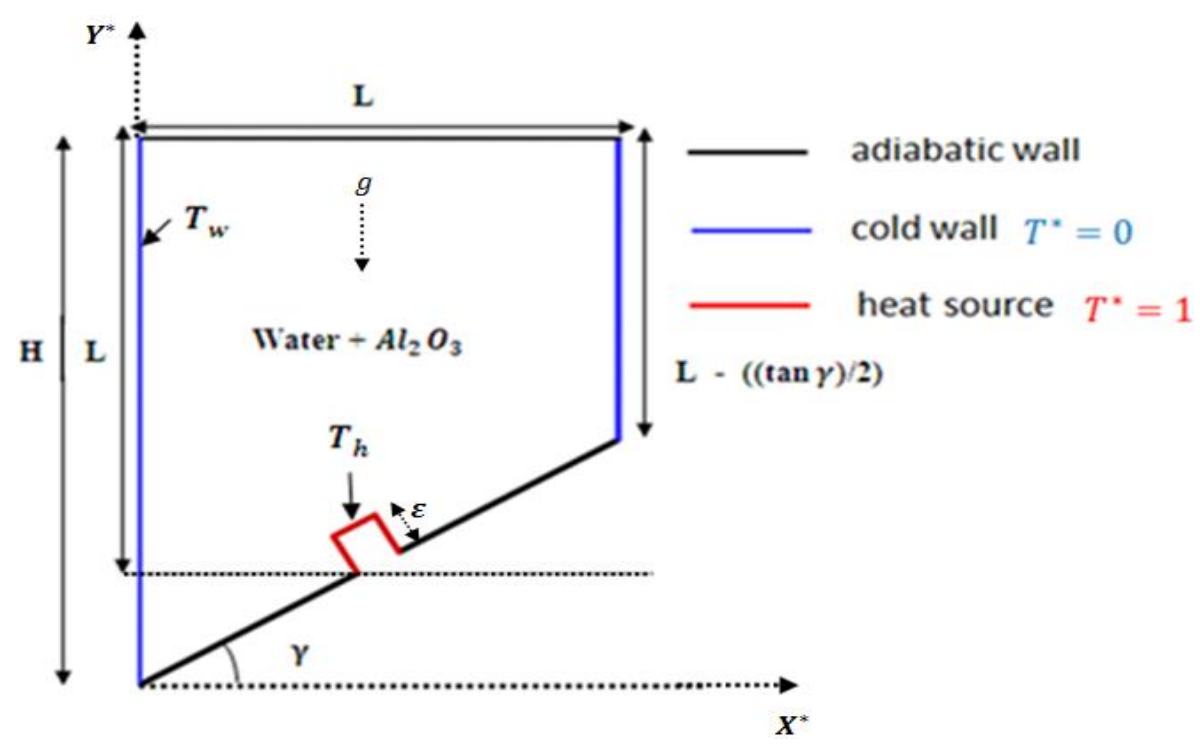

Fig. 1. Physical model

\subsubsection{Governing equation}

In Cartesian coordinates and taking account of the simplifying assumptions supposed above, the equations governing the problem are

Continuity equation:

$\frac{\partial \mathrm{U}}{\partial \mathrm{X}}+\frac{\partial \mathrm{V}}{\partial \mathrm{Y}}=0$

Momentum equation in $\mathrm{X}^{*}, \mathrm{Y}^{*}$ directions:

$\mathrm{U} \frac{\partial \mathrm{U}}{\partial \mathrm{X}}+\mathrm{V} \frac{\partial \mathrm{U}}{\partial \mathrm{Y}}=-\frac{1}{\rho_{\mathrm{nf}}} \frac{\partial \mathrm{P}}{\partial \mathrm{X}}+\frac{\mu_{\mathrm{nf}}}{\rho_{\mathrm{nf}}}\left(\frac{\partial^{2} \mathrm{U}}{\partial \mathrm{X}^{2}}+\frac{\partial^{2} \mathrm{U}}{\partial \mathrm{Y}^{2}}\right)$

$\mathrm{U} \frac{\partial \mathrm{V}}{\partial \mathrm{X}}+\mathrm{V} \frac{\partial \mathrm{V}}{\partial \mathrm{Y}}=-\frac{1}{\rho_{\mathrm{nf}}} \frac{\partial \mathrm{P}}{\partial \mathrm{Y}}+\frac{\mu_{\mathrm{nf}}}{\rho_{\mathrm{nf}}}\left(\frac{\partial^{2} \mathrm{~V}}{\partial \mathrm{X}^{2}}+\frac{\partial^{2} \mathrm{~V}}{\partial \mathrm{Y}^{2}}\right)+\frac{\mathrm{g}\left(\mathrm{T}-\mathrm{T}_{\mathrm{C}}\right)(\rho \beta)_{\mathrm{nf}}}{(\rho)_{\mathrm{nf}}}$

Energy equation:

$\mathrm{U} \frac{\partial \mathrm{T}}{\partial \mathrm{X}}+\mathrm{V} \frac{\partial \mathrm{T}}{\partial \mathrm{Y}}=\alpha_{\mathrm{nf}}\left(\frac{\partial^{2} \mathrm{~T}}{\partial \mathrm{X}^{2}}+\frac{\partial^{2} \mathrm{~T}}{\partial \mathrm{Y}^{2}}\right)$

with $\quad \alpha_{\mathrm{nf}}=\frac{\mathrm{K}_{\mathrm{nf}}}{\left(\rho c_{\mathrm{p}}\right)_{\mathrm{nf}}}$

and $\quad\left(\rho c_{p}\right)_{n f}=(1-\varphi)\left(\rho c_{p}\right)_{f}+\varphi\left(\rho c_{p}\right)_{s}$

The thermal conductivity of nanofluid is expressed by the relation of Wasp. 
$\mathrm{K}_{\mathrm{nf}}=\mathrm{K}_{\mathrm{f}} \frac{(2-2 \varphi) \mathrm{k}_{\mathrm{f}}+(1+\varphi) \mathrm{K}_{\mathrm{s}}}{(2+\varphi) \mathrm{k}_{\mathrm{f}}+(1-\varphi) \mathrm{K}_{\mathrm{s}}}$

The effective dynamic viscosity of nanofluid can be calculated by using the relation of Brinkman for a mixture.

$\mu_{\mathrm{nf}}=\frac{\mu_{\mathrm{f}}}{(1-\varphi)^{2.5}}$

The density of nanofluid is expressed by using the volume fraction.

$(\rho)_{\mathrm{nf}}=(1-\varphi)(\rho)_{\mathrm{f}}+\varphi(\rho)_{\mathrm{s}}$

Eq. (1) to (4) can be converted to the dimensionless forms by using the following parameters:

$\left(X^{*}, Y^{*}\right)=\frac{(X, Y)}{H},\left(U^{*}, V^{*}\right)=\frac{(U, V) * H}{\alpha_{f}}, T^{*}=\frac{T-T_{W}}{T_{h}-T_{w}}, P^{*}=\frac{P * H^{2}}{\rho_{n f} \alpha_{f}^{2}}, \frac{H}{L}=1+\left(\frac{\tan (\gamma)}{2}\right)$

Therefore, using the above settings leads to dimensionless forms of the governing equations as below

$\frac{\partial \mathrm{U}^{*}}{\partial \mathrm{X}^{*}}+\frac{\partial \mathrm{V}^{*}}{\partial \mathrm{Y}^{*}}=0$

$\mathrm{U}^{*} \frac{\partial \mathrm{U}^{*}}{\partial \mathrm{X}^{*}}+\mathrm{V}^{*} \frac{\partial \mathrm{U}^{*}}{\partial \mathrm{Y}^{*}}=-\frac{\partial \mathrm{P}^{*}}{\partial \mathrm{X}^{*}}+\frac{\operatorname{Pr}}{(1-\varphi)^{2.5}\left(1-\varphi+\varphi \mathrm{R}_{\rho}\right)}\left(\frac{\partial^{2} \mathrm{U}^{*}}{\partial \mathrm{X}^{* 2}}+\frac{\partial^{2} \mathrm{U}^{*}}{\partial \mathrm{Y}^{* 2}}\right)$

$\mathrm{U}^{*} \frac{\partial \mathrm{V}^{*}}{\partial \mathrm{X}^{*}}+\mathrm{V}^{*} \frac{\partial \mathrm{V}^{*}}{\partial \mathrm{Y}^{*}}=-\frac{\partial \mathrm{P}^{*}}{\partial \mathrm{Y}^{*}}+\frac{\operatorname{Pr}}{(1-\varphi)^{2.5}\left(1-\varphi+\varphi \mathrm{R}_{\rho}\right)}\left(\frac{\partial^{2} \mathrm{~V}^{*}}{\partial \mathrm{X}^{* 2}}+\frac{\partial^{2} \mathrm{~V}^{*}}{\partial \mathrm{Y}^{* 2}}\right)+\frac{(1-\varphi)+\varphi \mathrm{R}_{\beta} \mathrm{R}_{\rho}}{(1-\varphi)+\varphi \mathrm{R}_{\rho}} \operatorname{RaPr}^{*}$

$\mathrm{U}^{*} \frac{\partial \mathrm{T}^{*}}{\partial \mathrm{X}^{*}}+\mathrm{V}^{*} \frac{\partial \mathrm{T}^{*}}{\partial \mathrm{Y}^{*}}=\frac{(2-2 \varphi)+(1+\varphi) \mathrm{R}_{\mathrm{k}}}{\left((2+\varphi)+(1-\varphi) \mathrm{R}_{\mathrm{k}}\right)\left((1-\varphi)+(\varphi) \mathrm{R}_{\left(\rho c_{p}\right)}\right)}\left(\frac{\partial^{2} \mathrm{~T}^{*}}{\partial \mathrm{X}^{* 2}}+\frac{\partial^{2} \mathrm{~T}^{*}}{\partial \mathrm{Y}^{* 2}}\right)$

where figure the following dimensionless numbers and ratio.

$\operatorname{Pr}=\frac{\mu_{f}}{\rho_{f} a_{f}}, R a=\frac{g \beta_{f} H^{3}\left(T_{h}-T_{c}\right)}{v_{f} \cdot \alpha_{f}}, R_{\rho}=\frac{\rho_{s}}{\rho_{f}}, R_{k}=\frac{K_{s}}{K_{f}}, R_{\left(\rho c_{p}\right)}=\frac{\left(\rho c_{p}\right)_{s}}{\left(\rho c_{p}\right)_{f}}$

The dimensionless boundaries conditions are given in Table 1.

Table 1

Dimensionless boundaries conditions

\begin{tabular}{lll}
\hline Upper wall & $U^{*}=V^{*}=0$ & $\frac{\partial T^{*}}{\partial Y^{*}}=0$ \\
Lower wall inclined on both sides of the heat source & $U^{*}=V^{*}=0$ & $\frac{\partial T^{*}}{\partial n^{*}}=0$ \\
& & $T^{*}=0$ \\
Left and right wall & $U^{*}=V^{*}=0$ & $T^{*}=1$ \\
At the heat source & $U^{*}=V^{*}=0$ & $T^{*}$
\end{tabular}


The Thermo-physical properties of water and solid nanoparticles [6] are given in Table 2.

\section{Table 2}

Thermo-physical properties of water and solid nanoparticles

\begin{tabular}{lllllll}
\hline & $\mathrm{Pr}$ & $\rho$ & $C_{P}$ & $\mathrm{~K}$ & $\beta \times 10^{-5}$ & $\alpha \times 10^{-7}$ \\
\hline water & 7 & 997.1 & 4179 & 0.613 & 21 & 1.47 \\
$\mathrm{Al}_{2} \mathrm{O}_{3}$ & - & 3970 & 765 & 40 & 0.85 & 131.7 \\
\hline
\end{tabular}

\section{Results and Discussion}

The finite elements method is used in our model for discrediting the governing equations in Eq. (10) to (13) along with the boundary conditions.

To describe the structure of the flow in the cavity we fix the following settings of the nanofluid (Water- $\mathrm{Al}_{2} \mathrm{O}_{3}$ )

$\operatorname{Pr}=7, R_{\rho}=3.981, R_{k}=65, R_{\left(\rho c_{p}\right)}=0.728$

\subsection{Thermal Fields}

In Figure 2 to 5 , the pivoting bottom of the cavity provided with a fixed heat source in the middle, whose inclination $\gamma$ varied from 0 to 60 degrees and the Rayleigh number Ra from $10^{3}$ to $10^{6}$ in order to see the influence of these parameters on the thermal field represented by the contours of the isotherms, therefore on the heat transfer represented by the volume fractions $\varphi$ varying from 0 to $10 \%$ (see the Figure 11(c), (d), and 13(e), (f)).

They show at the optimal angle $\left(\gamma=60^{\circ}\right)$, for different values of the volume fraction and Rayleigh number, the existence of an almost symmetry of the isotherms with respect to the median bottom of the trapezoidal cavity considered.

For $\mathrm{Ra}=10^{3}$, almost all the isothermal contours are represented by elliptical curves concentrated around the heat source where the transfer mode is practically conductive, this phenomenon loses its existence from $\mathrm{Ra}=10^{4}$ giving rise to the distortion of the curves which are accentuated with the increase in the number of Rayleigh Ra.

The increase in the number of Rayleigh Ra and more precisely from Ra $=10^{5}$, the thermal field takes on a plume form and causes the deformation of the isotherms giving rise to the birth of the convective phenomenon.

The convective phenomenon is intensified with the increase in the number of Rayleigh Ra where it becomes most dominant for large Rayleigh values $\left(\mathrm{Ra}=10^{6}\right)$. This implies an increase in heat transfer through the bottom of the cavity. The stratification of the isotherms is clearly observed and the thickness of the thermal boundary layer decreases with the increase in the number of Rayleigh Ra.

The highest temperature is that of the nanofluid which circulates in the hot region, while the lowest temperature that which circulates parallel to the cold sides and therefore, he heats up in contact with the heated area, cools down in contact with the cold sides. 

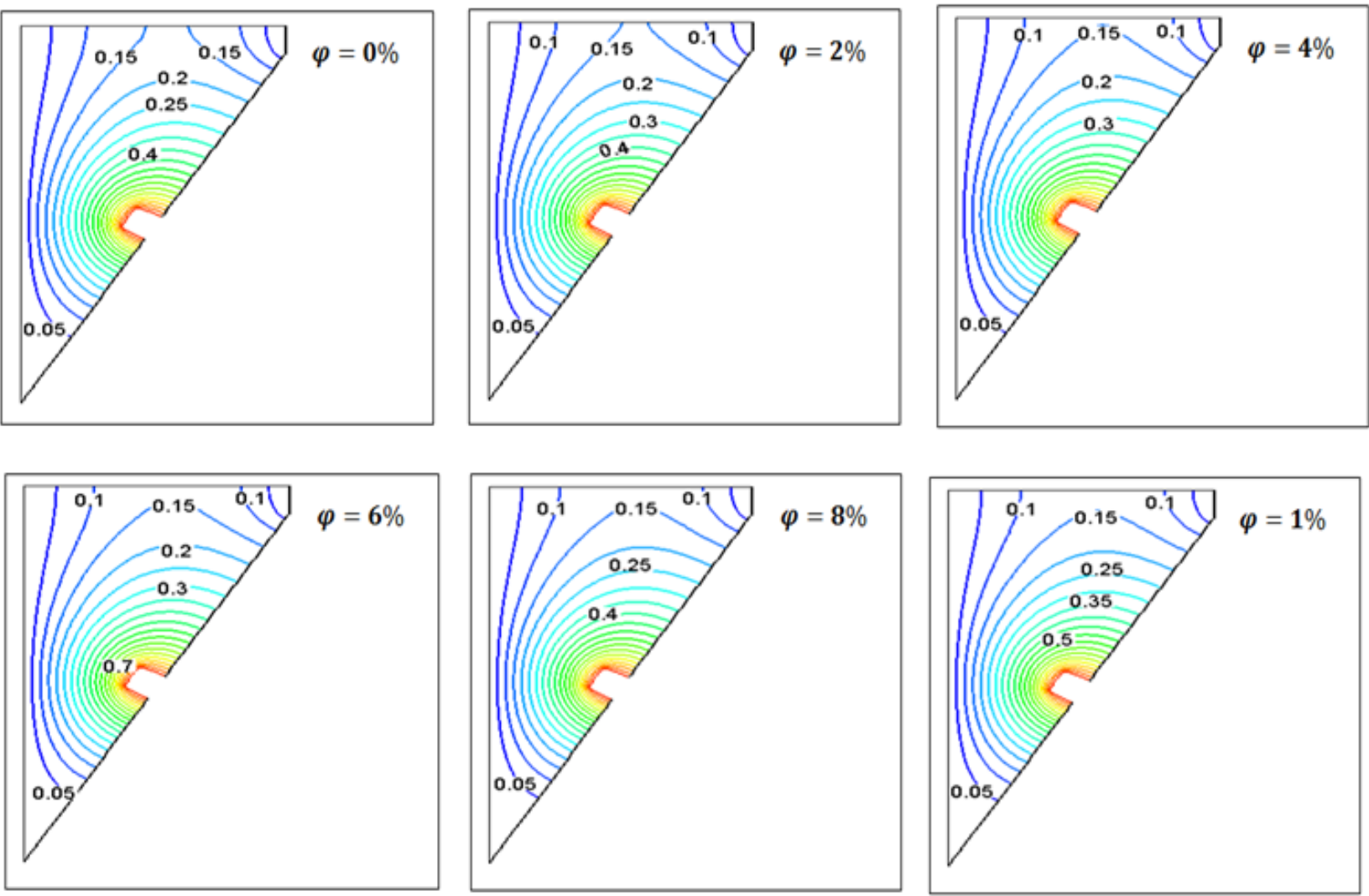

Fig. 2. Isotherms for $\mathrm{Ra}=10^{3}$ and $\gamma=60^{\circ}$
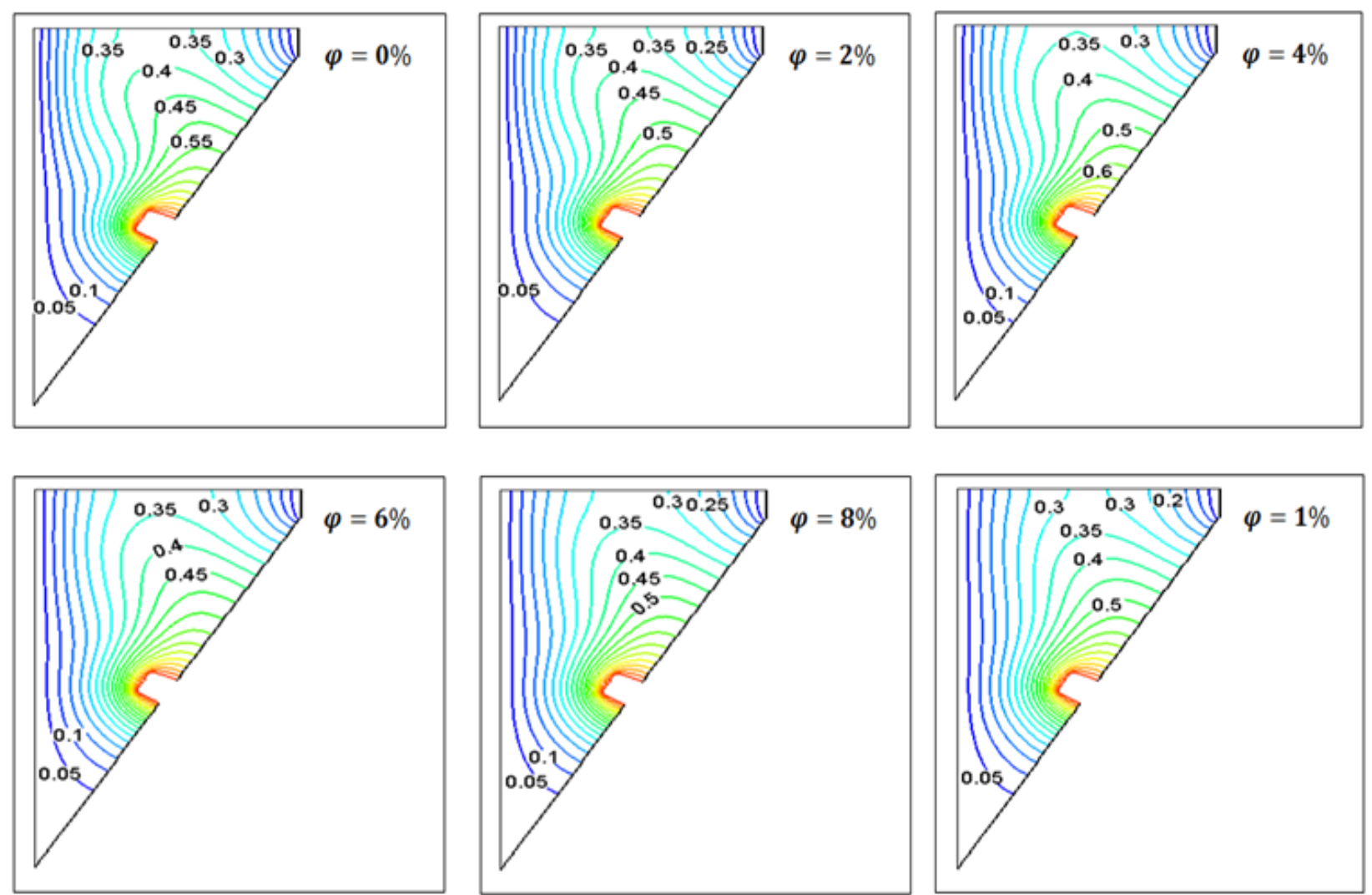

Fig. 3. Isotherms for $\mathrm{Ra}=10^{4}$ and $\gamma=60^{\circ}$ 

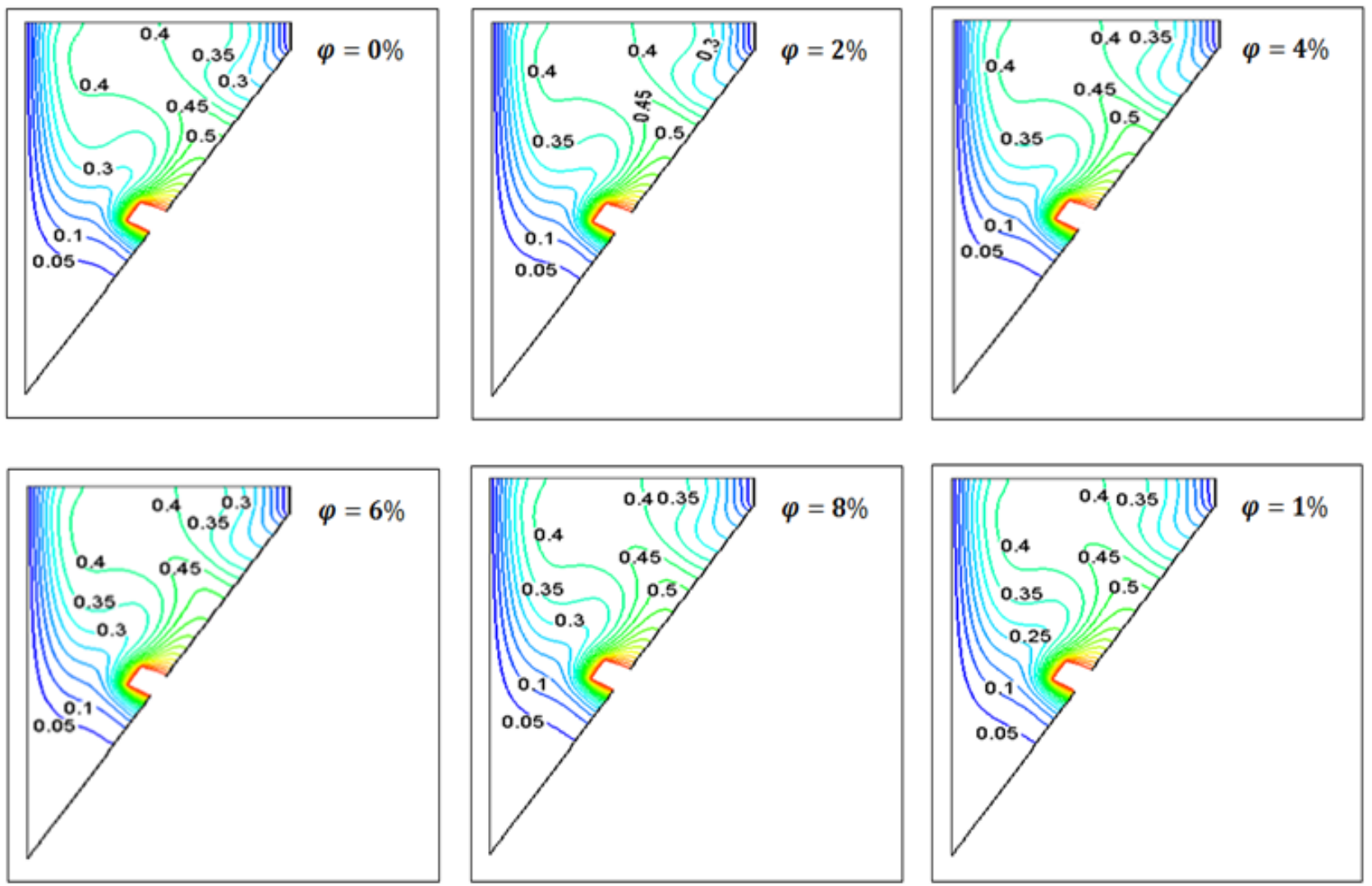

Fig. 4. Isotherms for $\mathrm{Ra}=10^{5}$ and $\gamma=60^{\circ}$
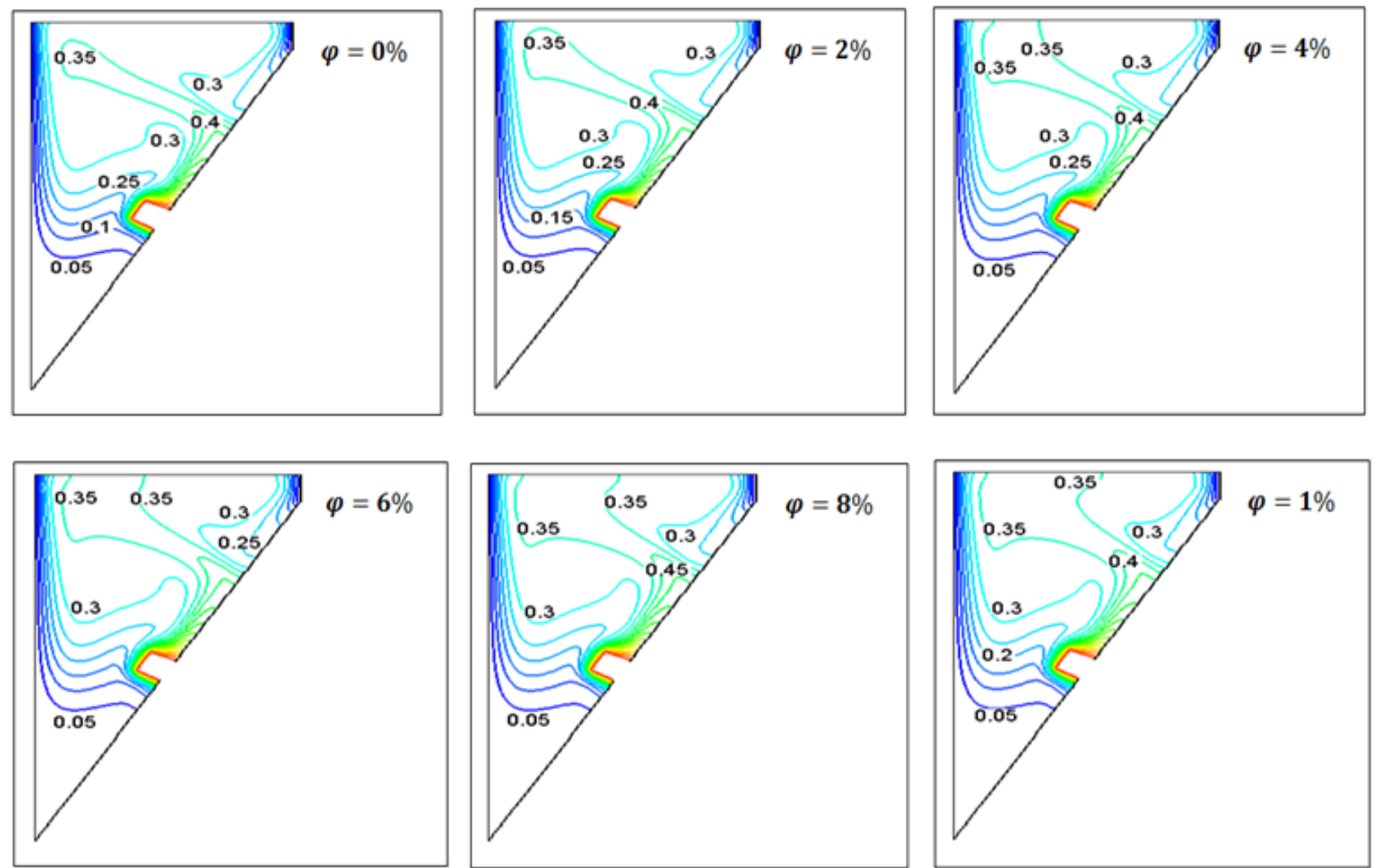

Fig. 5. Isotherms for $\mathrm{Ra}=10^{6}$ and $\gamma=60^{\circ}$ 


\subsection{Dynamic Fields}

Figure 6 to 9 show the contours of the stream lines with the same parameters already mentioned in order to see again these influences on the dynamic field. For $\mathrm{Ra}=10^{3}$, the flow structure is formed by a single cell which occupies the whole of the cavity.

From the Rayleigh $\mathrm{Ra}=10^{4}$, this cell is divided into two parts at the top and bottom of which the bottom one occupies almost the entire cavity, just at the level of the Rayleigh $R a=10^{5}$, that of the bottom in turn decreases and subdivided into two, the other increases with the increase in the number of Rayleigh, by finally obtaining three cells inside the cavity giving rise to a much more intense acceleration of nanofluid particles.
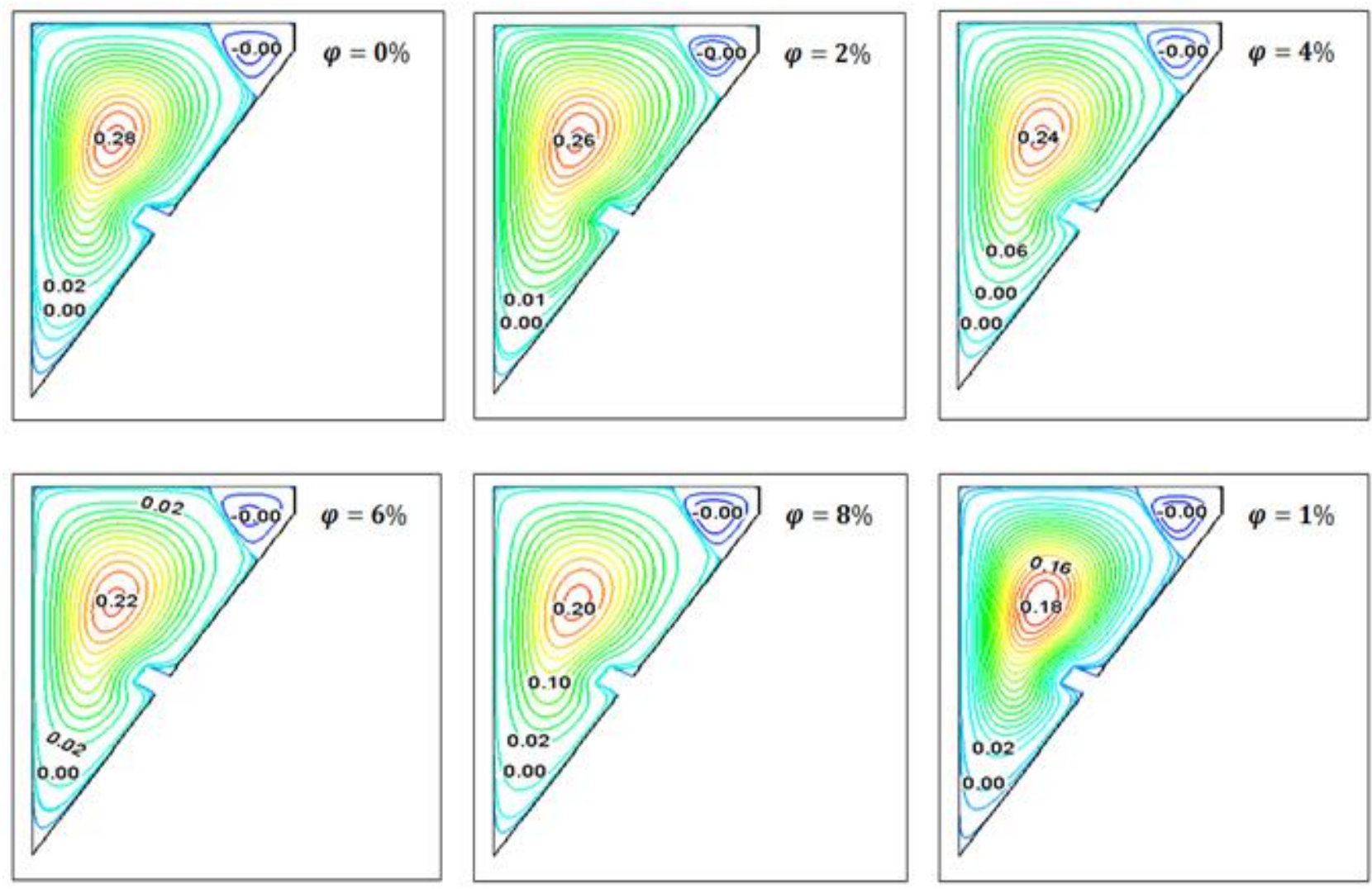

Fig. 6. Stream lines for $\mathrm{Ra}=10^{3}$ and $\gamma=60^{\circ}$ 

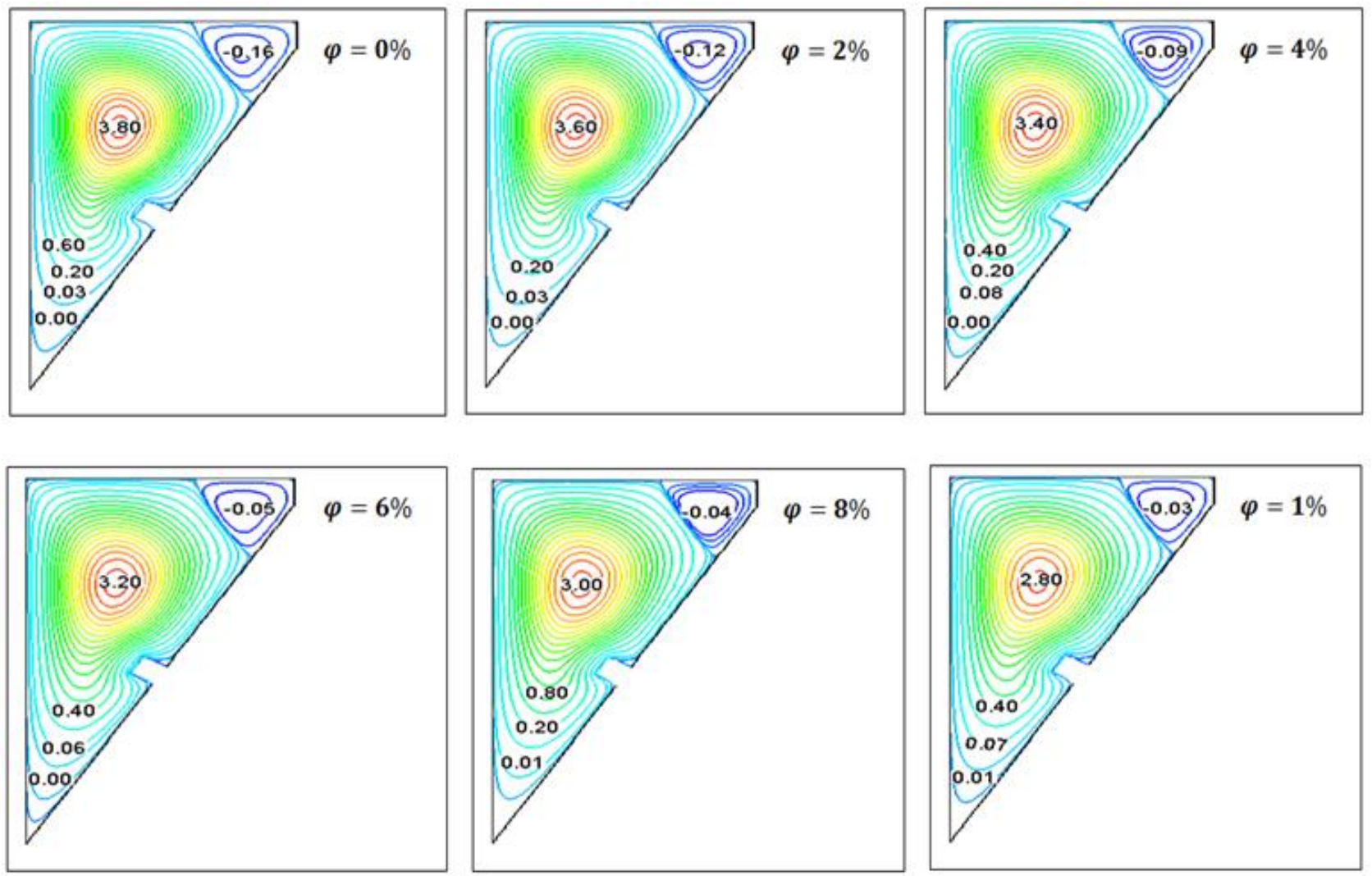

Fig. 7. Stream lines for $\mathrm{Ra}=10^{4}$ and $\gamma=60^{\circ}$
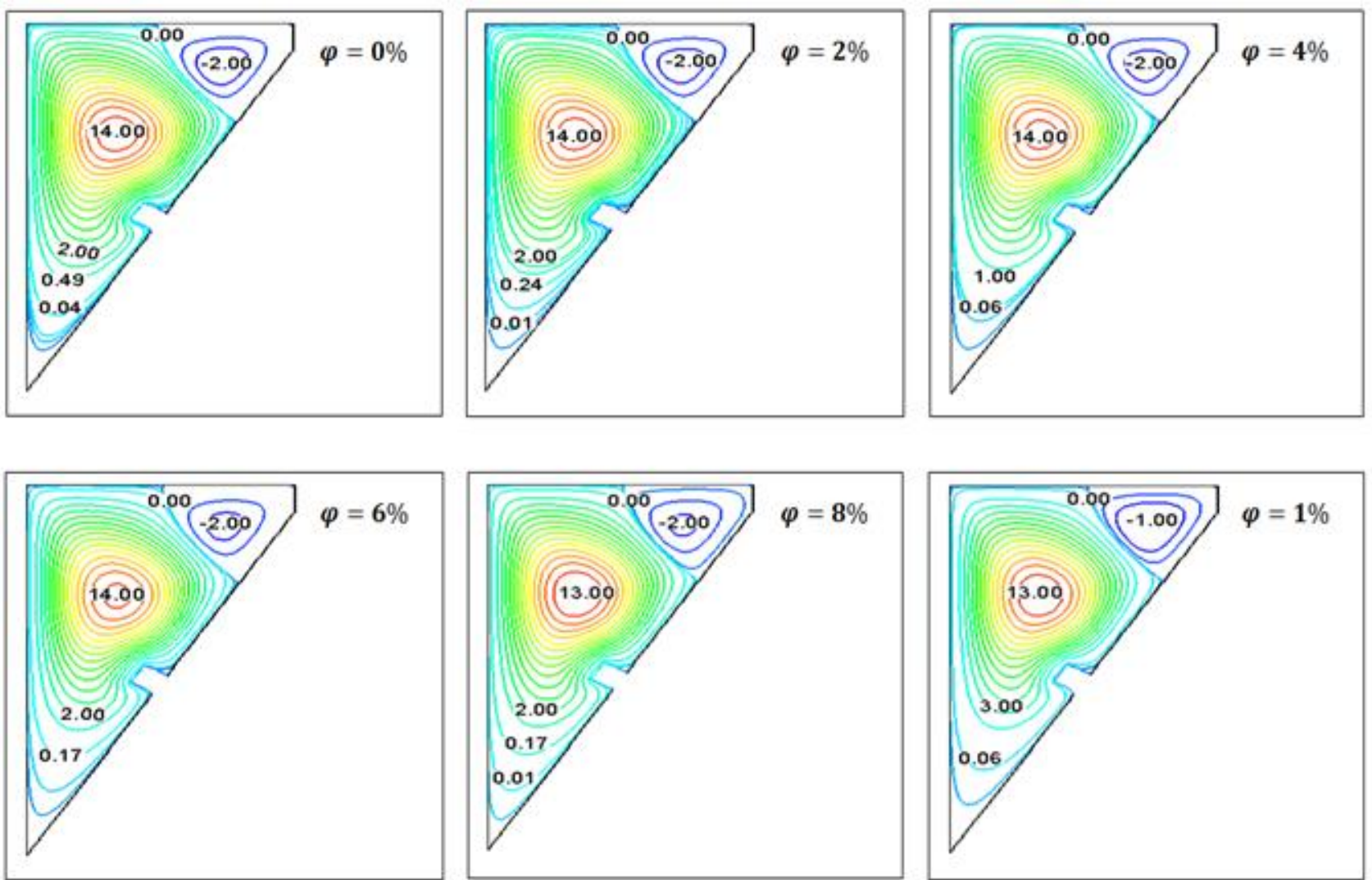

Fig. 8. Stream lines for $\mathrm{Ra}=10^{5}$ and $\gamma=60^{\circ}$ 

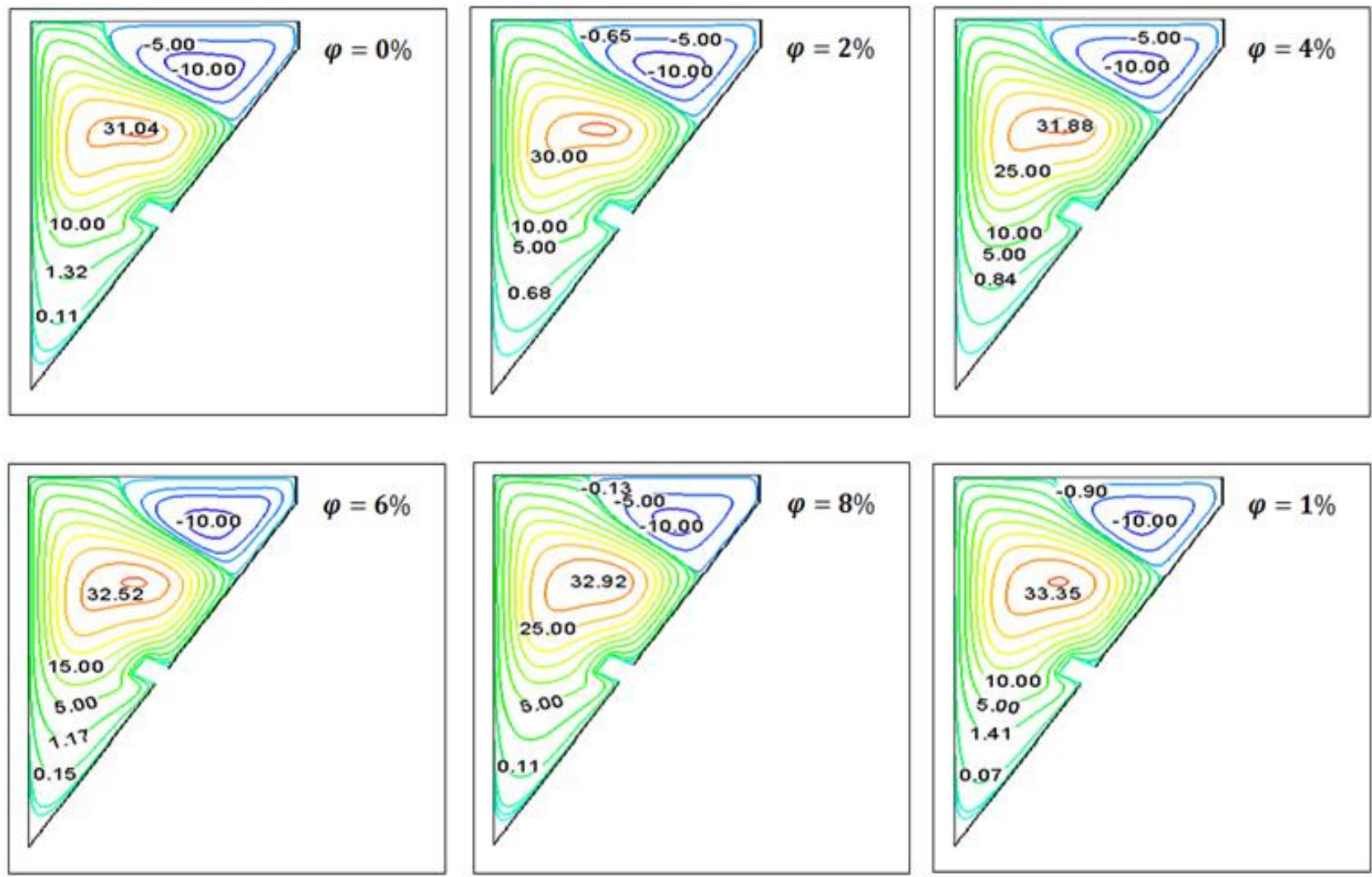

Fig. 9. Stream lines for $\mathrm{Ra}=10^{6}$ and $\gamma=60^{\circ}$

\subsection{Nusselt Number}

Figure 10 to 14 show the change of the local and average Nusselt number along the cavity's height $H$ respectively for different inclination, solid volume fraction and the Rayleigh number.

they show the effect of the solid volume fraction $\varphi$, the angle of inclination $\gamma$ of the pivoting lower wall of the cavity and Rayleigh Ra on the heat transfer.

Because of these settings, the cavity is composed of two distinct zones: a hot and a cold one. Keeping the number of Rayleigh unchanged, the hot zone increases with the increase of the solid volume fraction (Figure 11(c), (d), and Figure 13(e), (f)) and the angle of inclination of the lower wall of the cavity (Figure 10(a), (b), and Figure 14(h)).

In addition to a given solid volume fraction, the heat transfer rate increases with Rayleigh number's increase (Figure 12, Figure 14(e)).

$N u_{l}^{*}=\frac{K_{n f}}{K_{f}}\left(\frac{\partial T^{*}}{\partial n^{*}}\right)$

The higher numbers of Rayleigh, cause stronger effects of solid volume fraction on thermal and dynamic fields (Figure 11(d), and Figure 13(f)).

Changes in local Nusselt number in terms of volume fraction $\varphi$, along the height $\mathrm{H}$ of the cavity, have a maximum value that increases with the increase of the nanofluid concentration (Figure 11(d)).

The average Nusselt number varies almost directly according to the solid volume fraction (Figure $14(\mathrm{~g}))$.

For a Rayleigh value less than $\mathrm{Ra}=10^{3}$ and a concentration change from $0 \%$ to $10 \%$, the heat transfer rate increases by almost 25\% (Figure 14(g)). 


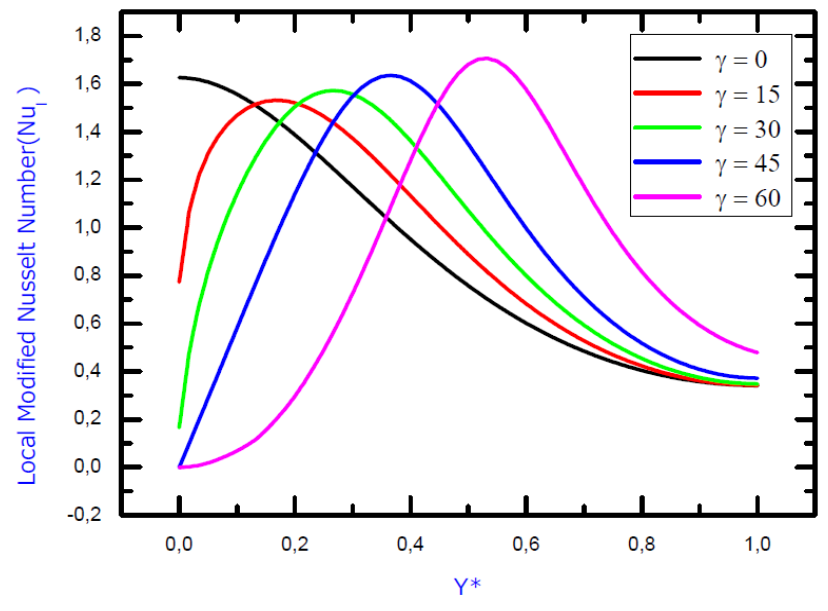

(a)

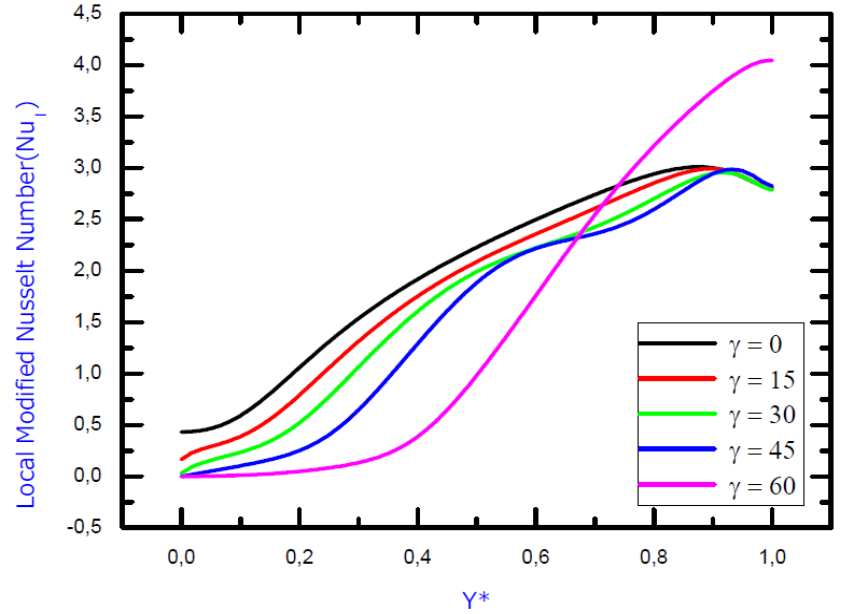

(b)

Fig. 10. Change of local Nusselt number along the left wall of the cavity respectively for (a) $R a=10^{3}$, (b) $R a=$ $10^{5}$ for a volume fraction $\varphi=5 \%$

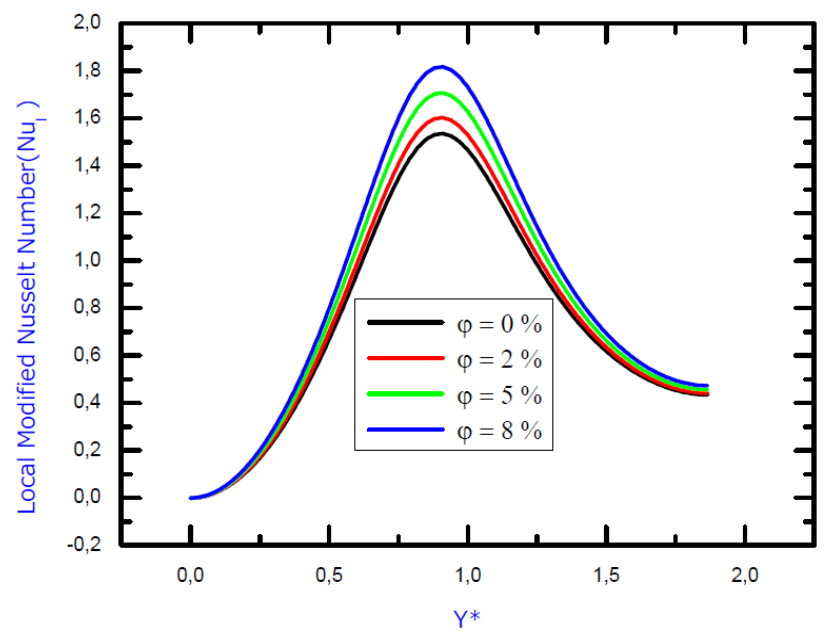

(c)

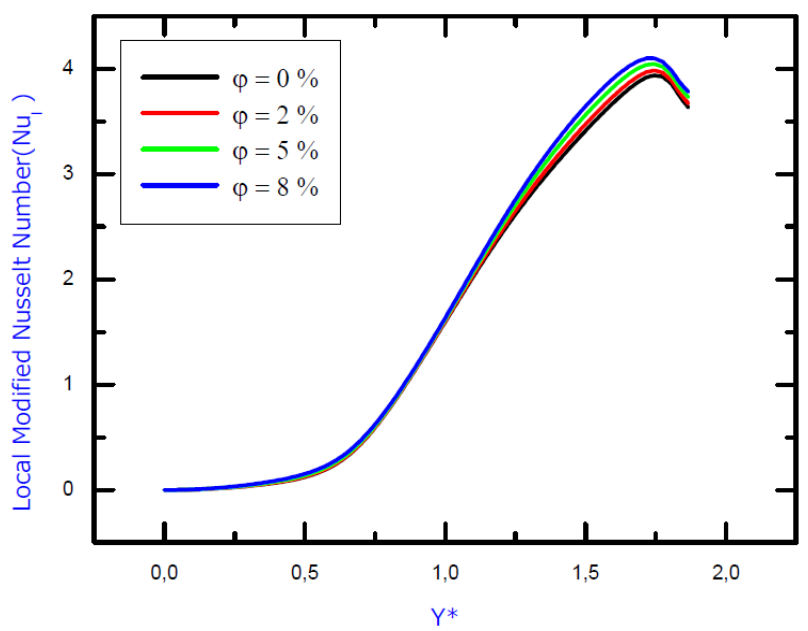

(d)

Fig. 11. Change of local Nusselt number along the left wall of the cavity respectively for (c) $R a=10^{3}$, (d) $R a=$ $10^{5}$ for the angle of inclination $\gamma=60^{\circ}$

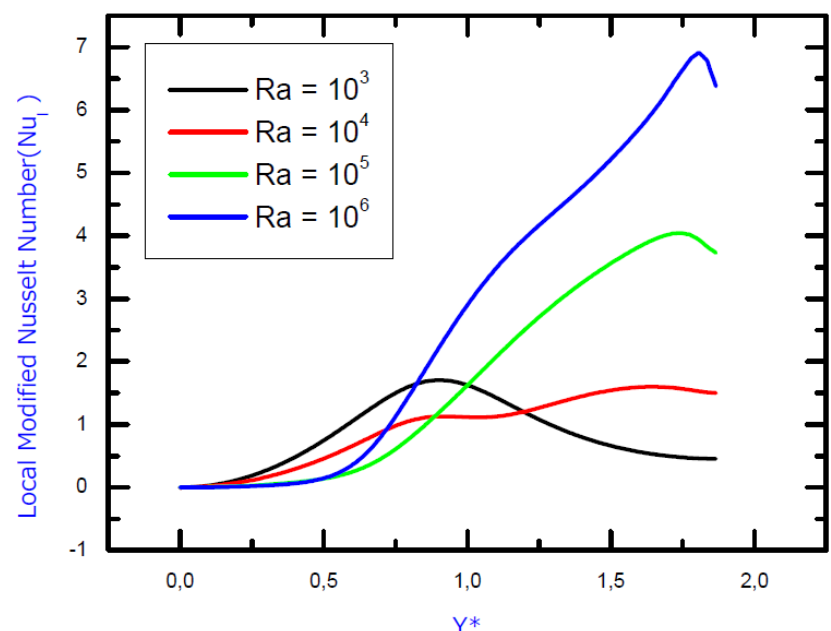

Fig. 12. Change of local Nusselt number along the left wall of the cavity for the angle of inclination $\gamma=$ $60^{\circ}$ and volume fraction $\varphi=5 \%$ 


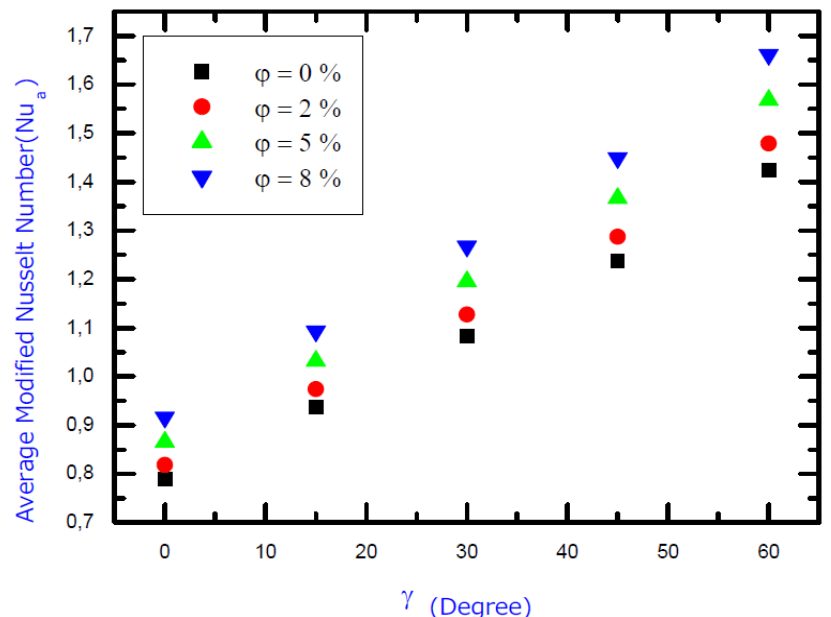

(e)

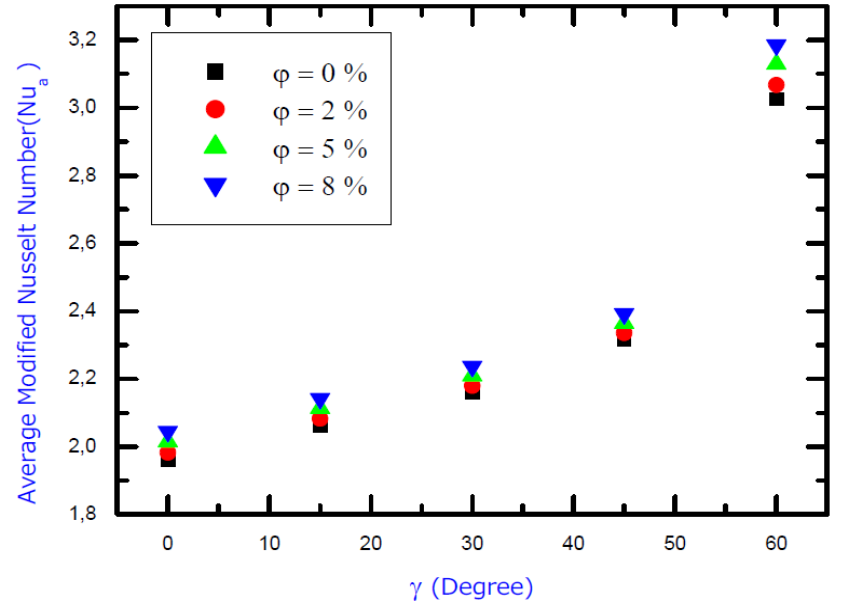

(f)

Fig. 13. Change of the average Nusselt number according to the angle of inclination of the lower wall of the cavity respectively for (e) $\mathrm{Ra}=10^{3}$, (f) $\mathrm{Ra}=10^{5}$

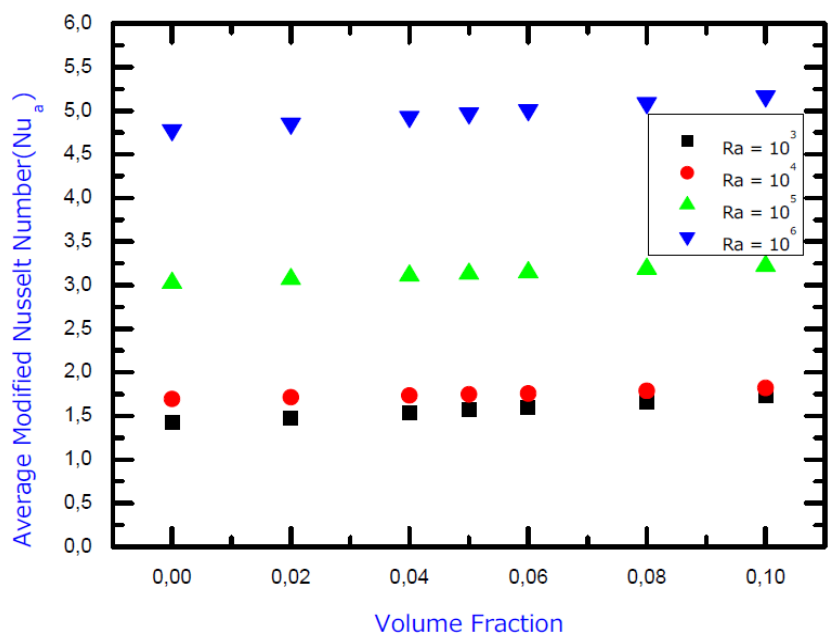

(g)

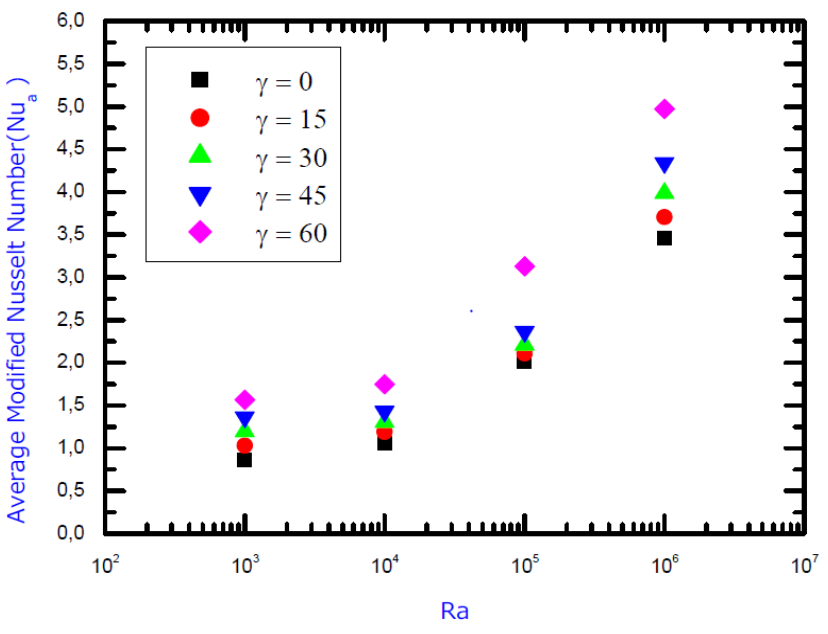

(h)

Fig. 14. Change of the average Nusselt number according respectively to the volume fraction ( $\mathrm{g}), \mathrm{Ra}(\mathrm{h})$ of the lower wall of the cavity for $\gamma=60^{\circ}$, volume fraction $=5 \%$

\section{Conclusion}

The two-dimensional natural convection fluid flow and heat transfer in a cavity whose form is subject to the mathematical relation $A=H / L=1+(\tan (\gamma) / 2$ with a heat source placed at middle of its bottom wall and filled with nanofluid water based have been simulated numerically.

This paper examines the heat transfer enhancement of this nanofluid $\left(A L_{2} O_{3}+\right.$ water) with constant temperature heating numerically for arrange of inclination angles, solid volume fractions, and Rayleigh numbers. The results show that

i. The rate of heat transfer increases with the increase in the volume fraction in nanoparticles and the Rayleigh number.

ii. The effect of nanoparticles on heat transfer is more important at low Rayleigh numbers.

iii. The rate of heat transfer increases with increasing angle of inclination of the bottom of the cavity which leads to good geometric design, good cooling of the heat source and this is the case for the trapezoidal cavity at the optimal angle of inclination $\gamma=60^{\circ}$ compared to a square cavity of $\gamma=0^{\circ}$. 


\section{References}

[1] Choi, Stephen US, and Jeffrey A. Eastman. Enhancing thermal conductivity of fluids with nanoparticles. No. ANL/MSD/CP-84938; CONF-951135-29. Argonne National Lab., IL (United States), 1995.

[2] Choi, S. U. S., Z. G. Zhang, WLockwoodFE Yu, F. E. Lockwood, and E. A. Grulke. "Anomalous thermal conductivity enhancement in nanotube suspensions." Applied physics letters 79, no. 14 (2001): 2252-2254. https://doi.org/10.1063/1.1408272

[3] Eastman, Jeffrey A., S. U. S. Choi, Sheng Li, W. Yu, and L. J. Thompson. "Anomalously increased effective thermal conductivities of ethylene glycol-based nanofluids containing copper nanoparticles." Applied physics letters 78 , no. 6 (2001): 718-720. https://doi.org/10.1063/1.1341218

[4] Keblinski, P., Eastman, J.A. and Cahill, D.G., 2005. Nanofluids for thermal transport. Materials today, 8(6), pp.3644. https://doi.org/10.1016/S1369-7021(05)70936-6

[5] Yang, Ying, Z. George Zhang, Eric A. Grulke, William B. Anderson, and Gefei Wu. "Heat transfer properties of nanoparticle-in-fluid dispersions (nanofluids) in laminar flow." International journal of heat and mass transfer 48, no. 6 (2005): 1107-1116. https://doi.org/10.1016/i.ijheatmasstransfer.2004.09.038

[6] Daungthongsuk, Weerapun, and Somchai Wongwises. "A critical review of convective heat transfer of nanofluids." Renewable and sustainable energy reviews 11, no. 5 (2007): 797-817. https://doi.org/10.1016/i.rser.2005.06.005

[7] Vadasz, Peter. "Heat conduction in nanofluid suspensions." Journal of heat transfer 128, no. 5 (2006): $465-477$. https://doi.org/10.1115/1.2175149

[8] Masuda, Hidetoshi, Akira Ebata, and Kazumari Teramae. "Alteration of thermal conductivity and viscosity of liquid by dispersing ultra-fine particles. Dispersion of Al2O3, SiO2 and TiO2 ultra-fine particles." Netsu Bussei 7, no. 4 (1993): 227-233. https://doi.org/10.2963/ijtp.7.227

[9] Eastman, Jeffery A., U. S. Choi, Shaoping Li, L. J. Thompson, and Shinpyo Lee. Enhanced thermal conductivity through the development of nanofluids. No. ANL/MSD/CP-90462; CONF-961202-94. Argonne National Lab., IL (United States), 1996.

[10] Wang, X., Xu, X. and Choi, S.U., 1999. Thermal conductivity of nanoparticle-fluid mixture. Journal of thermophysics and heat transfer, 13(4), pp.474-480. https://doi.org/10.2514/2.6486

[11] Lee, S., SU-S. Choi, S, and Li, and J. A. Eastman. "Measuring thermal conductivity of fluids containing oxide nanoparticles." Journal of Heat Transfer (1999): 280-289. https://doi.org/10.1115/1.2825978

[12] Das, Sarit Kumar, Nandy Putra, Peter Thiesen, and Wilfried Roetzel. "Temperature dependence of thermal conductivity enhancement for nanofluids." J. Heat Transfer 125, no. 4 (2003): 567-574. https://doi.org/10.1115/1.1571080

[13] Öğüt, Elif Büyük. "Natural convection of water-based nanofluids in an inclined enclosure with a heat source." International Journal of Thermal Sciences 48, no. 11 (2009): 2063-2073.

https://doi.org/10.1016/j.ijthermalsci.2009.03.014

[14] Fontana, Éliton, Adriano Da Silva, and Viviana Cocco Mariani. "Natural convection in a partially open square cavity with internal heat source: An analysis of the opening mass flow." International Journal of Heat and Mass Transfer 54, no. 7-8 (2011): 1369-1386. https://doi.org/10.1016/i.ijheatmasstransfer.2010.11.053

[15] Sheikhzadeh, G. A., A. Arefmanesh, M. H. Kheirkhah, and R. Abdollahi. "Natural convection of Cu-water nanofluid in a cavity with partially active side walls." European Journal of Mechanics-B/Fluids 30, no. 2 (2011): 166-176. https://doi.org/10.1016/i.euromechflu.2010.10.003

[16] Oztop, Hakan F., Yasin Varol, Ahmet Koca, and Mujdat Firat. "Experimental and numerical analysis of buoyancyinduced flow in inclined triangular enclosures." International communications in heat and mass transfer 39, no. 8 (2012): 1237-1244. https://doi.org/10.1016/j.icheatmasstransfer.2012.06.011

[17] Aminossadati, S. M. "Hydromagnetic natural cooling of a triangular heat source in a triangular cavity with waterCuO nanofluid." International communications in heat and mass transfer 43 (2013): 22-29.

https://doi.org/10.1016/j.icheatmasstransfer.2013.02.009 
[18] Hu, Yang, Decai Li, Shi Shu, and Xiaodong Niu. "Natural convection in a nanofluid-filled eccentric annulus with constant heat flux wall: A lattice Boltzmann study with immersed boundary method." International Communications in Heat and Mass Transfer 86 (2017): 262-273.

https://doi.org/10.1016/j.icheatmasstransfer.2017.05.015

[19] Guestal, Mabrouk, Mahfoud Kadja, and Mai Ton Hoang. "Study of heat transfer by natural convection of nanofluids in a partially heated cylindrical enclosure." Case studies in thermal engineering 11 (2018): 135-144. https://doi.org/10.1016/i.csite.2018.01.008

[20] Ferhi, Mokhtar, Ridha Djebali, and Said Abboudi. "Conjugate Natural Convection in a Partitioned Square Cavity Filled with Al2O3-Water Nanofluid Based on Experimental Correlations: A Lattice Boltzmann investigation." CFD Letters 11, no. 3 (2019): 1-27.

[21] Sawicka, Dorota, Albert Baars, Janusz T. Cieśliński, and Sławomir Smoleń. "Numerical simulation of natural convection of Glycol-Al2O3 nanofluids from a horizontal cylinder." Heat Transfer Engineering (2019): 1-9. https://doi.org/10.1080/01457632.2019.1699303

[22] COMSOL Multiphysics Reference Manual, version 3.5a, COMSOL, Inc, www.comsol.com. 